\title{
A progressive increase in cardiovascular risk assessed by coronary angiography in non- diabetic patients at sub-diabetic glucose levels
}

\author{
Sven Schinner ${ }^{1 \dagger}$, Reiner Füth ${ }^{2 \dagger}$, Kerstin Kempf ${ }^{3,4 \dagger}$, Stephan Martin ${ }^{3}$, Holger S Willenberg ${ }^{1}$, Matthias Schott ${ }^{1}$,
} Wilfried Dinh ${ }^{2}$, Werner A Scherbaum ${ }^{1}$ and Mark Lankisch ${ }^{2 *}$

\begin{abstract}
Objective: Diabetes mellitus type 2 (DM2) is a risk factor for coronary heart disease (CHD). While there is a clear correlation of fasting blood glucose (FBG) and $2 \mathrm{~h}$ post-challenge blood glucose values (2h-BG) with microvascular complications, the risk for CHD conferred by glucose dysregulation antecedent to DM2 is less clear. Therefore, we investigated associations of FBG and 2h-BG values with the prevalence of CHD assessed by coronary angiography as the most sensitive diagnostic tool.
\end{abstract}

Research Design and Methods: Coronary angiography was performed in 1394 patients without known DM. Capillary blood glucose was analyzed before and $2 \mathrm{~h}$ after an oral glucose tolerance test. Associations between FBG as well as $2 \mathrm{~h}-\mathrm{BG}$ levels and the risk for CHD were assessed by logistic regression analysis.

Results: 1064 (75\%) of patients were diagnosed with CHD. 204 (15\%) were diagnosed with so far unknown DM2, 274 (20\%) with isolated impaired fasting glucose (IFG), 188 (13\%) with isolated impaired glucose tolerance (IGT) and 282 (20\%) with both, IGT and IFG. We found a continuous increase in the risk for CHD with fasting and postchallenge blood glucose values even in the subdiabetic range. This correlation did however not suggest clear cutoff values. The increase in risk for CHD reached statistical significance at FBG levels of $>120 \mathrm{mg} / \mathrm{dl}$ (Odds Ratio of 2.7 [1.3-5.6] and 2h-BG levels $>140 \mathrm{mg} / \mathrm{dl}$ (141-160 mg/dl OR 1.8 [1.1-2.9], which was however lost after adjusting for age, sex and BMI.

Conclusions: In our study population we found a continuous increased risk for CHD at fasting and 2h-BG levels in the sub-diabetic glucose range, but no clear cut-off values for cardiovascular risk.

Keywords: impaired glucose tolerance, impaired fasting glucose, diabetes mellitus, oral glucose tolerance test, cardiovascular disease

\section{Introduction}

Diabetes mellitus type 2 (DM2) is a major risk factor for micro- and macrovascular complications like coronary heart disease (CHD) [1,2]. While there is a clear correlation of fasting blood glucose (FBG) and $2 \mathrm{~h}$ post-challenge blood glucose values (2h-BG) with microvascular diseases, the risk for CHD conferred by glucose dysregulation antecedent to DM2 is less clear. There is controversial data concerning the correlation of blood glucose

\footnotetext{
* Correspondence: lankisch@t-online.de

+ Contributed equally

${ }^{2}$ Heart Center, Helios Clinic Wuppertal, Wuppertal, Germany

Full list of author information is available at the end of the article
}

levels in the sub-diabetic range (impaired fasting glucose (IFG) and impaired glucose tolerance (IGT)) with the cardiovascular risk. The controversies might be due to different clinical end-points. Frequently used end-points are all-cause and cardiovascular mortality. Using allcause mortality as an end-point Sorkin et al found a significant $40 \%$ increase in risk when the FBG exceeded $110 \mathrm{mg} / \mathrm{dl}$ [3]. This was in line with the Rancho Bernado study and the IPC Center study[4,5]. This increase in mortality further doubled within the FBG range between $126 \mathrm{mg} / \mathrm{dl}$ and $139 \mathrm{mg} / \mathrm{dl}[3]$. There might also be gender differences as data from the Rancho Bernado study showed a significant increase in mortality within 
the FBG range between $100-110 \mathrm{mg} / \mathrm{dl}$ in men but not in women [6,7].

Consistently, a number of studies found a continuous increase in all-cause mortality with FBG levels in the sub-diabetic range although they did not reach statistical significance[8-11].

On the other hand, there are data from other studies reporting no correlation between FBG and mortality in the subdiabetic range[6].

Similarly, the relation between IGT and cardiovascular risk remains unclear. The ARIC study for example found no association of IGT with cardiovascular risk over a 6.3 year follow-up period[12]. However, the largest meta-analysis in that area including 20 prospective studies and almost 100000 individuals revealed an increased cardiovascular risk for people with IGT when analysing clinical cardiovascular events[13].

In order to clarify the association of subdiabetic glucose values and cardiovascular risk we have chosen coronary angiography as a sensitive clinical end-point in the current study. Coronary atherosclerosis precedes the clinical manifestation of CHD and can be diagnosed early by coronary angiography. Patients undergoing coronary angiography show a high prevalence of undiagnosed glucose abnormalities[14]. There is only limited data on the correlation of glucose dysregulation with coronary atherosclerosis assessed by angiography. The only large cohort $(\mathrm{n}=1040)$ has been reported by Saely and colleagues. They investigated the relation of impaired glucose tolerance (2h-BG levels in an oGTT) with angiographically characterised coronary atherosclerosis. They found IGT to be associated with an increased prevalence of coronary atherosclerosis but not with significant stenosis (defined as lumen narrowing > 50\%)[15]. To our knowledge there is no data from a large cohort on angiographically assessed CHD in correlation to fasting blood glucose levels in the subdiabetic range. Therefore, the aim of this study was to investigate if the prevalence of coronary stenosis assessed by coronary angiography is increased at subdiabetic glucose levels.

\section{Methods}

\section{Study population}

All patients $(\mathrm{n}=1394)$ without known DM2 that have been submitted to the heart center Wuppertal (Germany) for elective coronary angiography between 2007 and 2009 were enrolled in this retrospective study. The study was performed according to the rules of the Declaration of Helsinki and all study patients gave informed written consent. The clinical and demographic data obtained for each patient included sex, age, body mass index (BMI), history of CHD and actual cardiovascular intervention.

\section{Determination of coronary and glycaemic state}

In each patient, coronary angiography was performed at least one day before the oGTT. Coronary heart disesase (CHD) was diagnosed in the presence of a luminal narrowing $\geq 50 \%$ of any epicardial vessel. An oGTT with 75 g (DextroOGT, Roche Diagnostics, Mannheim, Germany) was performed and capillary blood glucose was measured before and $2 \mathrm{~h}$ after oral glucose load with a point-of-care system (ecoSolo II; CAREdiagnostica), which is based on enzymatic, amperometric measurement using a GOD- $\mathrm{H}_{2} \mathrm{O}_{2}$ electrode. Coefficient of variation was about $5 \%$. Of note, classifications of glycaemic state were made according to the criteria of the German Diabetes Association (Deutsche Diabetes Gesellschaft) for capillary blood glucose (IFG $>90 \mathrm{mg} / \mathrm{dl}$; IGT $>140$ $\mathrm{mg} / \mathrm{dl} ; \mathrm{DM} 2 \geq 110 \mathrm{mg} / \mathrm{dl}$ (fasting) or $\geq 200 \mathrm{mg} / \mathrm{dl}$ (2hBG after oGTT)). For one patient the FBG value was missing. 2h-BG values were missing for 20 patients since there FBG values had been considerably higher than $110 \mathrm{mg} / \mathrm{dl}$. Therefore, OGTT had not been performed in those cases and DM2 had been diagnosed based on the FBG values.

\section{Statistical analysis}

Logistic regression analysis with adjustment to sex and age was used to determine the influence of FBG or 2hBG on CHD risk. Associations were determined by Spearman correlation. The level of significance was 0.05. For data analysis GraphPad Prism 4.0 (GraphPad Software, San Diego, CA, USA) and SAS statistical package version 8.2 TS2MO (SAS Institute, Cary, NC, USA) were used.

\section{Results}

High prevalence of coronary heart disease in the study population

In this study we enrolled 1,394 patients without known DM2 who underwent elective coronary angiography. The patient characteristics are given in Table 1. As shown here, $76 \%$ of the patients were diagnosed with CHD based on the lumen narrowing $\geq 50 \%$ diagnosed by coronary angiography. The prevalence of CHD correlated with age $(\mathrm{r}=0.12, \mathrm{p}<0.0001)$, male sex $(\mathrm{r}=0.23$; $\mathrm{p}<0.0001)$, the diagnosis of DM2 $(\mathrm{r}=0.08 ; \mathrm{p}=0.003)$, FBG $(r=0.07 ; p=0.009)$, and 2H-BG $(r=0.14 ; p<$ 0.0001 ). Using an oGTT $15 \%$ of the patients were identified with so far unknown DM2, 20\% with isolated IFG, $13 \%$ with isolated IGT and 20\% with both IGT and IFG. Only $32 \%$ were normoglycaemic (Table 1 ).

\section{Increased risk for coronary heart disease with blood glucose levels in the subdiabetic range}

Capillary blood glucose was determined in the fasting state and $2 \mathrm{~h}$ after an oGTT. The distribution of FBG 
Table 1 Patient characteristics

\begin{tabular}{|c|c|}
\hline & Patients $(n=1394)$ \\
\hline Sex [n] (male/female) & $962(69 \%) / 432(31 \%)$ \\
\hline Age [years] & $64.0 \pm 11.4$ \\
\hline Body Mass Index $\left[\mathrm{kg} / \mathrm{m}^{2}\right]$ & $27.6 \pm 4.5$ \\
\hline $\mathrm{CHD}[\mathrm{n}]$ & $1064(76 \%)$ \\
\hline Acute myocardial infarction [n] & $294(21 \%)$ \\
\hline CHD before [n] & $579(42 \%)$ \\
\hline FBG [mg/dl] & $92.5 \pm 16.2$ \\
\hline $2 \mathrm{~h}-\mathrm{BG}[\mathrm{mg} / \mathrm{dl}]$ & $145.0 \pm 43.1$ \\
\hline NGT [n] & $446(32 \%)$ \\
\hline Isolated IFG [n] & $274(20 \%)$ \\
\hline Isolated IGT [n] & $188(13 \%)$ \\
\hline $\mathrm{IFG} / \mathrm{IGT}[\mathrm{n}]$ & $282(20 \%)$ \\
\hline $\mathrm{DM} 2[\mathrm{n}]$ & $204(15 \%)$ \\
\hline
\end{tabular}

CHD, coronary heart disease; FBG, fasting blood glucose; $2 \mathrm{~h}-\mathrm{BG}$, blood glucose $2 \mathrm{~h}$ after $75 \mathrm{~g}$ oral glucose challenge; NGT, normal glucose tolerance; IFG, impaired fasting glucose; IGT, impaired glucose tolerance; DM, diabetes mellitus

levels among the patients was as followed: 435 (31\%) were $<90 \mathrm{mg} / \mathrm{dl}$ (329 with CHD vs. 106 without CHD), $370(26 \%)$ were in the range of $91-100 \mathrm{mg} / \mathrm{dl}(292 \mathrm{vs}$. $78), 164(12 \%)$ were between $101-110 \mathrm{mg} / \mathrm{dl}$ (124 vs. 40), 76 (6\%) were between $111-120 \mathrm{mg} / \mathrm{dl}$ (62 vs. 14) and $72(5 \%)$ were $>120 \mathrm{mg} / \mathrm{dl}$ (63 vs. 9) (Figure 1A). Patients with $\mathrm{FBG} \leq 80 \mathrm{mg} / \mathrm{dl}(\mathrm{n}=276(20 \%) ; 200$ vs. 76) were defined as the reference group. Compared to the reference group the risk for CHD increased continuously with FBG levels. Table 2 shows that statistical significance was reached at FBG levels $>120 \mathrm{mg} / \mathrm{dl}$ (OR 2.67 [1.3-5.6]) and remained significant after adjusting for sex and age but not in a separate model including the BMI. As seen in Table 3 when blood glucose was expressed as a continuous variable, both the fasting as well as the $2 \mathrm{~h}$ glucose values were significantly correlated with CHD risk.

Consistently, Table 4 shows a continuous risk increment for CHD over the whole range of glucose levels.

When analysing post-challenge glucose, we found 181 (13\%) of the patients had 2h-BG values ranging 101-120 $\mathrm{mg} / \mathrm{dl}$ (196 vs. 67), 291 (21\%) were in the range of 121 $140 \mathrm{mg} / \mathrm{dl}$ (200 vs. 91$), 212(15 \%)$ in the range of 141 $160 \mathrm{mg} / \mathrm{dl}$ (170 vs. 42$), 161$ (12\%) were between 161$180 \mathrm{mg} / \mathrm{dl}$ (142 vs. 19), and $266(19 \%)$ were > $180 \mathrm{mg} / \mathrm{dl}$ (221 vs. 45) (Figure 1B). Patients with $2 \mathrm{~h}$-BG levels $\leq 100 \mathrm{mg} / \mathrm{dl}$ ( $\mathrm{n}=181(13 \%) ; 125$ vs. 56$)$ were defined as the reference group. Similarly to our findings for fasting glucose the CHD risk increased at subdiabetic $2 \mathrm{~h}$ glucose levels with an increased risk for CHD with an OR 1.80 [1.1-2.9] for patients within the glucose range of $141-160 \mathrm{mg} / \mathrm{dl}, 2.2$ [1.4-3.4] for those within 161-180 $\mathrm{mg} / \mathrm{dl}$ and 3.3 [1.8-5.8] for patients whose 2h-BG exceeded $180 \mathrm{mg} / \mathrm{dl}$ (Table 2).

\section{Discussion}

In our study population $76 \%$ of patients were diagnosed with CHD and $15 \%$ with so far unknown DM2, 20\% with IFG, $13 \%$ with IGT and $20 \%$ with both, IFG and IGT. DM2 is a major risk factor for coronary heart disease[16]. However, the diagnostic thresholds to define diabetes are based on microvascular endpoints. Therefore, it is not clear whether microvascular and CHD risk increases at the same glucose thresholds. In our study, the risk for CHD as assessed by coronary angiography increased with the blood glucose levels even in the subdiabetic range. However, we found a rather continuous increase of CHD risk with blood glucose. In the fasting state the increase in risk reached statistical significance only when the capillary fasting glucose levels were $>120$ $\mathrm{mg} / \mathrm{dl}$. It is important to note that the diabetes threshold in the fasting state in capillary blood is $\geq 110 \mathrm{mg} / \mathrm{dl}$. Therefore, in our study IFG increased the risk for CHD but did not reach statistical significance. When analysing post-challenge glucose values we found a significant increase in CHD risk even at the level of IGT. The analysis of the combination of all grades of glucose disturbancies (IFG, IGT and diabetes) revealed a positive and significant correlation with CHD (table 3).

There is ongoing debate if there is at all a clear threshold for CHD risk or rather a continuous increase with increasing blood glucose levels. Therefore, the most important finding in our study is the increase in the prevalence of coronary heart disease with blood glucose levels in the subdiabetic range. Our results are in line with a large retrospective meta-analysis including 95,000 patients demonstrating an increase for cardiovascular events even at sub-diabetic glucose levels[13]. In addition, a recent meta-analysis identified a positive correlation between IGT and carotid intima media thickness as a marker for cardiovascular risk[17]. In line with this study we found that postprandial hyperglycaemia contributes more to CHD than fasting hyperglycaemia. However, various investigations on this question yielded controversial data. For example in the prospective ARIC (Atherosclerosis Risk in Communities) study there was no association of isolated IFG or IGT with cardiovascular risk. In line with this, a recent study by Pereg and colleagues attributed the progressive increase in cardiovascular risk at fasting glucose levels in the upper normal range to the prevalence of comorbidities rather than to glucose effects[18].

Notably, the endpoints in this study - as in most other similar studies - were clinical events. This included all cause mortality, clinically incident CHD and surrogate parameters for cardiovascular risk e.g. intima-media 


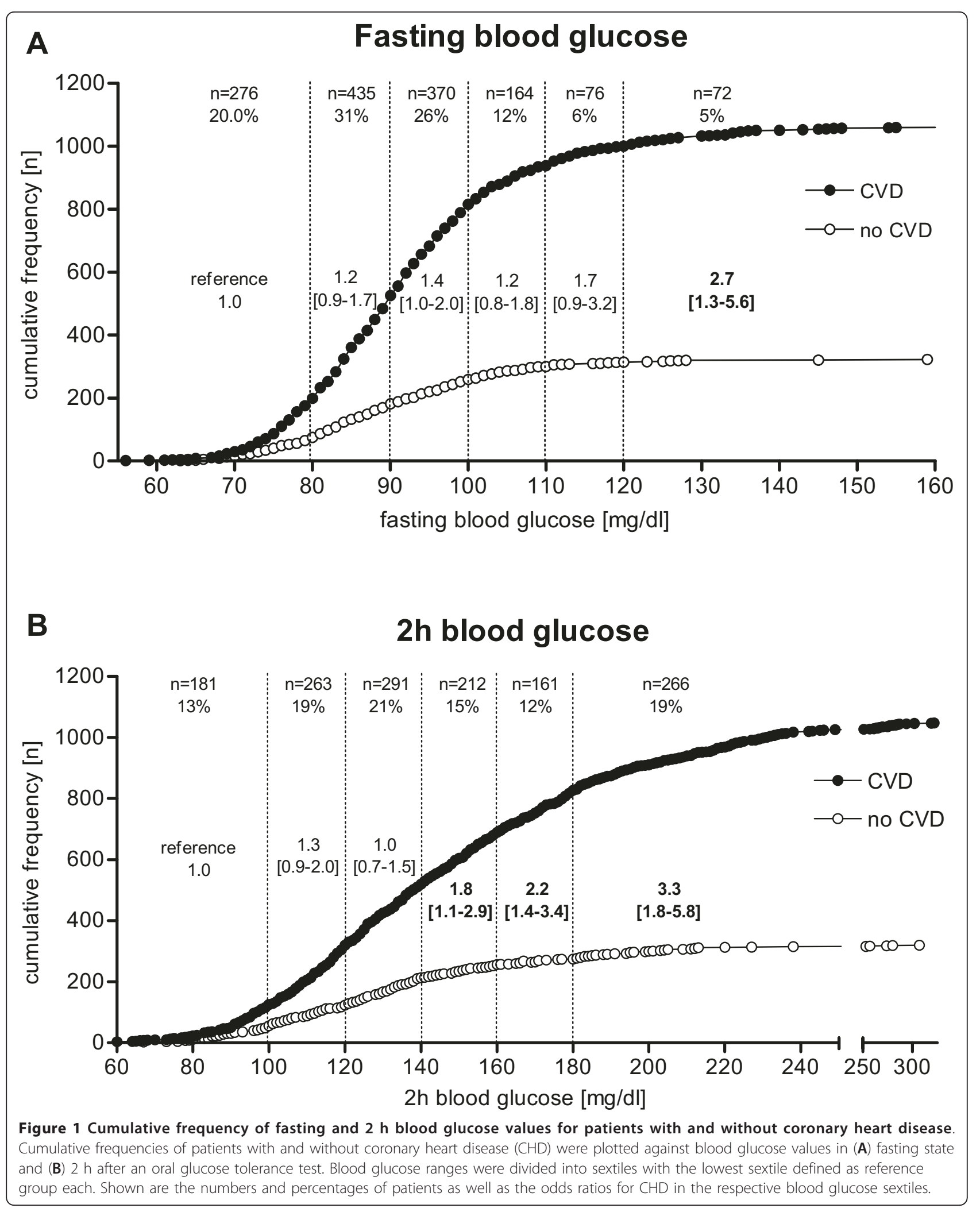


Table 2 Association between blood glucose levels and coronary heart disease.

\begin{tabular}{llll}
\hline $\begin{array}{l}\text { fasting blood glucose } \\
\text { [mg/dl] }\end{array}$ & $\begin{array}{l}\text { rohes OR } \\
{[\mathrm{Cl}]}\end{array}$ & adj. OR [CI] & $\begin{array}{l}\text { adj. OR [CI] } \\
\mathbf{2}\end{array}$ \\
\hline$\leq 80$ (reference) & 1.00 & 1.00 & 1.00 \\
\hline $81-90$ & $1.18[0.88-$ & $1.13[0.79-$ & $1.15[0.78-$ \\
& $1.66]$ & $1.64]$ & $1.71]$ \\
\hline $91-100$ & $1.42[0.99-$ & $1.24[0.85-$ & $1.27[0.84-$ \\
& $2.04]$ & $1.81]$ & $1.92]$ \\
\hline $101-110$ & $1.17[0.75-$ & $1.04[0.65-$ & $1.12[0.67-$ \\
& $1.83]$ & $1.67]$ & $1.87]$ \\
\hline $111-120$ & $1.69[0.89-$ & $1.39[0.71-$ & $1.41[0.67-$ \\
& $3.20]$ & $2.74]$ & $2.97]$ \\
\hline$>120$ & $\mathbf{2 . 6 7 [ 1 . 2 7 -}$ & $\mathbf{2 . 5 0 [ 1 . 1 5 -}$ & $2.27[0.93-$ \\
& $\mathbf{5 . 6 4 ]}$ & $\mathbf{5 . 4 6 ]}$ & $5.31]$ \\
\hline $\mathbf{2 ~ h ~ b l o o d ~ g l u c o s e ~ [ m g / /}$ & & & \\
dl] & & & \\
\hline$\leq 100$ (reference) & 1.00 & 1.00 & 1.00 \\
\hline $101-120$ & $1.30[0.86-$ & $1.17[0.74-$ & $0.99[0.61-$ \\
& $1.98]$ & $1.82]$ & $1.60]$ \\
\hline $121-140$ & $0.99[0.66-$ & $0.87[0.56-$ & $0.74[0.46-$ \\
& $1.47]$ & $1.33]$ & $1.17]$ \\
\hline $141-160$ & $\mathbf{1 . 8 0 [ 1 . 1 4 -}$ & $1.45[0.89-$ & $1.48[0.86-$ \\
& $\mathbf{2 . 8 6 ]}$ & $2.38]$ & $2.53]$ \\
\hline $161-180$ & $\mathbf{2 . 1 7}[1.40-$ & $\mathbf{2 . 1 8 [ 1 . 1 8 -}$ & $1.76[0.90-$ \\
& $\mathbf{3 . 3 7 ]}$ & $\mathbf{4 . 0 6}]$ & $3.45]$ \\
\hline$>180$ & $\mathbf{3 . 2 5 [ 1 . 8 3 -}$ & $1.53[0.92-$ & $1.44[0.80-$ \\
& $\mathbf{5 . 7 8 ]}$ & $2.53]$ & $2.57]$ \\
\hline
\end{tabular}

${ }^{1}$ adjusted for sex and age

2 adjusted for sex, age and bm

thickness, ankle-brachial blood pressure index and left ventricular hypertrophy.

However, coronary angiography is the current diagnostic gold standard for early detection of coronary artery disease[19]. Therefore, we investigated the correlation of blood glucose levels with data from patients undergoing elective coronary angiography.

Although patients with known DM2 had not been included in the study, two thirds of the patients had either IFG, IGT, or newly DM2 and only $32 \%$ of the patients included turned out to be normoglycaemic. This is in line with previous data[14,20] and

Table 2 Associations between blood glucose levels/ glucose tolerance state and coronary heart disease

\begin{tabular}{llll}
\hline & raw OR [CI] & adj. OR [Cl] & adj. OR [CI $]^{\mathbf{2}}$ \\
\hline fasting blood & 1.013 & 1.010 & 1.010 \\
glucose & {$[1.004-1.022]$} & {$[1.001-1.019]$} & {$[1.000-1.020]$} \\
\hline 2 h blood glucose & 1.008 & 1.007 & 1.007 \\
& {$[1.005-1.011]$} & {$[1.003-1.010]$} & {$[1.003-1.011]$} \\
\hline NGT/IFG+IGT/DM2 & 1.571 & 1.401 & 1.446 \\
combined & {$[1.292-1.910]$} & {$[1.147-1.727]$} & {$[1.158-1.807]$} \\
\hline adjusted for sex and age & & \\
${ }^{2}$ adjusted for sex, age and B.M.I. & &
\end{tabular}

Table 4 Difference in numbers of patients with or without coronary heart disease at defined blood glucose levels

\begin{tabular}{lc}
\hline fasting blood glucose $[\mathrm{mg} / \mathrm{dl}]$ & $\mathbf{p}$ \\
\hline$\leq 80$ vs. $>80$ & 0.067 \\
\hline$\leq 90$ vs. $>90$ & $\mathbf{0 . 0 3 1}$ \\
\hline$\leq 100$ vs. $>100$ & 0.171 \\
\hline$\leq 110$ vs. $>110$ & $\mathbf{0 . 0 1 8}$ \\
\hline$\leq 120$ vs. $>120$ & $\mathbf{0 . 0 3 1}$ \\
\hline $\mathbf{2}$ h blood glucose $[\mathrm{mg} / \mathrm{dl}]$ & \\
\hline$\leq 80$ vs. $>80$ & 0.153 \\
\hline$\leq 90$ vs. $>90$ & $\mathbf{0 . 0 0 1}$ \\
\hline$\leq 100$ vs. $>100$ & $\mathbf{0 . 0 1 1}$ \\
\hline$\leq 100$ vs. $>100$ & $\mathbf{0 . 0 0 9}$ \\
\hline$\leq 100$ vs. $>100$ & $<\mathbf{0 . 0 0 0 1}$ \\
\hline$\leq 100$ vs. $>100$ & $<\mathbf{0 . 0 0 0 1}$ \\
\hline$\leq 100$ vs. $>100$ & $\mathbf{0 . 0 0 6}$ \\
\hline
\end{tabular}

furthermore emphasises the importance of diagnostic efforts to detect DM2 in patients suspicious for CHD. How reliable are these oGTT data gained in hospital? A recent study reported follow-up data from oGTT tests done in hospital and after three months in patients with ST-elevation myocardial infarction. They found a large part of the study population to change the metabolic state with time[21]. However, it is not known, whether the patients were still critically ill during the in hospital oGTT. In our current study we had a different situation as we excluded patients with acute myocardial infarction.

There is very limited data on cardiovascular atherosclerosis assessed by angiography with respect to subdiabetic glucose levels. Earlier studies including relatively small numbers of patients that investigated the correlation of IGT with coronary artery disease by angiography demonstrated controversial results[22-25]. Only one large study by Saely and colleagues investigated coronary atherosclerosis by angiography with respect to IGT and found a positive correlation. In addition to this, our study correlates the risk for CHD defined as significant lumen narrowing with IGT and with distinct levels of FBG in the sub-diabetic range. We confirm the significant increase in CHD with IGT. In addition, there is the same trend of a continuous increase in CHD risk for fasting glucose values in the subdiabetic range; the effect was however significant only above the diabetes threshold. To our knowledge, this is the first study investigating this correlation in a large cohort of patients undergoing angiography. One hypothesis to explain this finding is that post-challenge glucose excursions contribute a greater CHD risk than slightly elevated fasting levels. 
Our study has several limitations: First, it is a retrospective study, therefore not directly allowing the prediction of future cardiovascular risk in patients at a given sub-diabetic glucose level. Second, we did not have the option to concisely include effects of co-medication (e.g. acetylsalicylic acid, statins) in our analysis. Third, we did not have a chance to evaluate the extent of coronary atherosclerosis. Instead, we defined the diagnosis of significant coronary stenosis when lumen narrowing was $\geq 50 \%$. However, based on the high number of patients included $(n=1394)$ we are confident that the effects of blood glucose on coronary atherosclerosis observed in our study are robust and reliable to assess the risk for coronary heart disease in the sub-diabetic glucose range. Interestingly, Saely et al. found a significant increase in the prevalence of coronary atherosclerosis (defined as any visible lumen narrowing) in patients with IGT but this was not significant for relevant stenosis (defined as lumen narrowing $>50 \%$ ). On the other hand, they found $2 \mathrm{~h}-\mathrm{BG}$ as a continuous variable to be significantly correlated with both prevalence of atherosclerosis and relevant stenosis[19]. In addition, a recent follow-up study on this population over 3.8 years showed a positive correlation of IFG with future cardiovascular events[26]. In line with this, we found not only 2h-BG but also FBG to be continuously correlated with increased prevalence of significant coronary stenosis. This seems to be in contrast to the effects of blood glucose on microvascular endpoints which show a steep increase of risk at distinct blood glucose values. Apparently, the risk of cardiovascular complications conferred by glucose is more a continuous gradual increase. This is important in identifying people at risk for cardiovascular disease in populations that do not fulfil the current diagnostic criteria of DM2. Taken together; our study demonstrates a continuous increase in cardiovascular risk at sub-diabetic glucose levels in patients undergoing elective coronary angiography.

\section{Acknowledgements}

This work was supported by a grant from the 'Nationales Aktionsforum Diabetes mellitus' (NAFDM).

\section{Author details \\ 'Department of Endocrinology, Diabetes and Rheumatology, University Hospital Düsseldorf; Germany. ${ }^{2}$ Heart Center, Helios Clinic Wuppertal, Wuppertal, Germany. ${ }^{3}$ West-German Centre of Diabetes and Health, Düsseldorf Catholic Hospital Group, Düsseldorf, Germany. ${ }^{4}$ Sana Hospital Gerresheim, Sana Clinics Düsseldorf GmbH, Düsseldorf, Germany.}

\section{Authors' contributions}

WAS, MS, SM made substantial contribution to conception and design. KK, SS, RF, WD and ML made substantial contributions to acquisition of data, or analysis and interpretation of data. HW has been involved in drafting the manuscript or revising it critically for important intellectual content. All authors read and approved the final manuscript.

\section{Conflict of interests}

The authors declare that they have no competing interests.

Received: 24 May 2011 Accepted: 24 June 2011 Published: 24 June 2011

\section{References}

1. Kannel WB, McGee DL: Diabetes and cardiovascular disease. The Framingham study. JAMA 1979, 241(19):2035-8.

2. Stamler J, Vaccaro O, Neaton JD, Wentworth D: Diabetes, other risk factors, and 12-yr cardiovascular mortality for men screened in the Multiple Risk Factor Intervention Trial. Diabetes Care 1993, 16(2):434-44

3. Sorkin JD, Muller DC, Fleg $J$, Andres R: The relation of fasting and 2-h postchallenge plasma glucose concentrations to mortality: data from the Baltimore Longitudinal Study of Aging with a critical review of the literature Diabetes Care 2005, 28(11):2626-32

4. Barrett-Connor E, Wingard DL, Criqui MH, Suarez L: Is borderline fasting hyperglycemia a risk factor for cardiovascular death? J Chronic Dis 1984 37(9-10):773-9.

5. Henry P, Thomas F, Benetos A, Guize L: Impaired fasting glucose, blood pressure and cardiovascular disease mortality. Hypertension 2002, 40(4):458-63.

6. Rodriguez BL, Abbott RD, Fujimoto W, Waitzfelder B, Chen R, Masaki K, Schatz I, Petrovitch H, Ross W, Yano K, Blanchette PL, Curb JD: The American Diabetes Association and World Health Organization classifications for diabetes: their impact on diabetes prevalence and total and cardiovascular disease mortality in elderly Japanese-American men. Diabetes Care 2002, 25(6):951-5.

7. Wei M, Gibbons LW, Mitchell TL, Kampert JB, Stern MP, Blair SN: Low fasting plasma glucose level as a predictor of cardiovascular disease and all-cause mortality. Circulation 2000, 101(17):2047-52.

8. Balkau B, Shipley $M$, Jarrett RJ, Pyörälä K, Pyörälä M, Forhan A, Eschwège E: High blood glucose concentration is a risk factor for mortality in middleaged nondiabetic men. 20-year follow-up in the Whitehall Study, the Paris Prospective Study, and the Helsinki Policemen Study. Diabetes Care 1998, 21(3):360-7.

9. Glucose tolerance and cardiovascular mortality: comparison of fasting and 2-hour diagnostic criteria. Arch Intern Med 2001, 161(3):397-405.

10. de Vegt F, Dekker JM, Ruhé HG, Stehouwer CD, Nijpels G, Bouter LM, Heine RJ: Hyperglycaemia is associated with all-cause and cardiovascular mortality in the Hoorn population: the Hoorn Study. Diabetologia 1999, 42(8):926-31.

11. Simons LA, Friedlander $Y$, McCallum J, Simons J: Fasting plasma glucose in non-diabetic elderly women predicts increased all-causes mortality and coronary heart disease risk. Aust N Z J Med 2000, 30(1):41-7.

12. Pankow JS, Kwan DK, Duncan BB, Schmidt MI, Couper DJ, Golden S, Ballantyne CM: Cardiometabolic risk in impaired fasting glucose and impaired glucose tolerance: the Atherosclerosis Risk in Communities Study. Diabetes Care 2007, 30(2):325-31.

13. Coutinho M, Gerstein HC, Wang Y, Yusuf S: The relationship between glucose and incident cardiovascular events. A metaregression analysis of published data from 20 studies of 95,783 individuals followed for 12.4 years. Diabetes Care 1999, 22(2):233-40.

14. Lankisch M, Füth R, Schotes D, Rose B, Lapp H, Rathmann W, Haastert B, Gülker H, Scherbaum WA, Martin S: High prevalence of undiagnosed impaired glucose regulation and diabetes mellitus in patients scheduled for an elective coronary angiography. Clin Res Cardiol 2006, 95(2):80-7.

15. Saely $\mathrm{CH}$, Drexel $H$, Sourij $H$, Aczel $S$, Jahnel $H$, Zweiker $R$, Langer $P$, Marte $T$, Hoefle G, Benzer W, Wascher TC: Key role of postchallenge hyperglycemia for the presence and extent of coronary atherosclerosis: an angiographic study. Atherosclerosis 2008, 199(2):317-22

16. Hadaegh F, Fahimfar N, Khalili D, Sheikholeslami F, Azizi F: New and known type 2 diabetes as coronary heart disease equivalent: results from 7.6 year follow up in a Middle East population. Cardiovasc Diabetol 2010, 9:84.

17. Einarson TR, Hunchuck J, Hemels M: Relationship between blood glucose and carotid intima media thickness: A meta-analysis. Cardiovasc Diabeto 2010, 9:37.

18. Pereg D, Elis A, Neuman $Y$, Mosseri M, Lishner M, Hermoni D: Cardiovascular risk in patients with fasting blood glucose levels within normal range. Am J Cardiol 2010, 106(11):1602-5. 
19. Fox K, Garcia MA, Ardissino D, Buszman P, Camici PG, Crea F, Daly C, De Backer G, Hjemdahl P, Lopez-Sendon J, Marco J, Morais J, Pepper J,

Sechtem U, Simoons M, Thygesen K, Priori SG, Blanc JJ, Budaj A, Camm J, Dean V, Deckers J, Dickstein K, Lekakis J, McGregor K, Metra M, Morais J, Osterspey A, Tamargo J, Zamorano JL: Guidelines on the management of stable angina pectoris: executive summary: The Task Force on the Management of Stable Angina Pectoris of the European Society of Cardiology. Eur Heart J 2006, 27(11):1341-81

20. Kempf K, Füth R, Dinh W, Bansemir L, Köhler T, Bufe A, Scheffold T, Standl E, Martin S, Lankisch M: Screening for overt diabetes by oral glucose tolerance test: Stratification by fasting blood glucose and patients' age improve practicability of guidelines in cardiological routine. Int J Cardiol 2010.

21. Knudsen EC, Seljeflot I, Michael A, Eritsland J, Mangschau A, Müller C, Arnesen $H$, Andersen $G \varnothing$ : Abnormal glucose regulation in patients with acute ST- elevation myocardial infarction-a cohort study on 224 patients. Cardiovasc Diabetol 2009, 8:6.

22. Fujiwara R, Kutsumi Y, Hayashi T, Kim SS, Misawa T, Tada H, Nishio H, Toyota K, Tamai T, Nakai T: Metabolic risk factors in the normolipidemic male patients with angiographically defined coronary artery disease. Jpn Circ J 1990, 54(5):493-500.

23. Horimoto M, Hasegawa A, Ozaki T, Takenaka T, Igarashi K, Inoue H: Independent predictors of the severity of angiographic coronary atherosclerosis: the lack of association between impaired glucose tolerance and stenosis severity. Atherosclerosis 2005, 182(1):113-9.

24. Seibaek M, Sloth C, Vallebo L, Hansen T, Urhammer SA, Burchardt H, TorpPedersen C, Pedersen O, Hildebrandt P: Glucose tolerance status and severity of coronary artery disease in men referred to coronary arteriography. Am Heart J 1997, 133(6):622-9.

25. Takeda Y, Mifune J, Taga K, Hifumi S, Takahashi Y, Yamashita S, Murakami T, Tanaka T: Multiple risk factors in coronary artery disease patients with abnormal glucose tolerance. Jpn Heart J 1991, 32(1):35-43.

26. Sourij H, Saely CH, Schmid F, Zweiker R, Marte T, Wascher TC, Drexel H: Post-challenge hyperglycaemia is strongly associated with future macrovascular events and total mortality in angiographied coronary patients. Eur Heart J 2010.

doi:10.1186/1475-2840-10-56

Cite this article as: Schinner et al: A progressive increase in

cardiovascular risk assessed by coronary angiography in non-diabetic patients at sub-diabetic glucose levels. Cardiovascular Diabetology 2011 10:56.

\section{Submit your next manuscript to BioMed Central and take full advantage of:}

- Convenient online submission

- Thorough peer review

- No space constraints or color figure charges

- Immediate publication on acceptance

- Inclusion in PubMed, CAS, Scopus and Google Scholar

- Research which is freely available for redistribution

Submit your manuscript at www.biomedcentral.com/submit 